\title{
Investigation of Polycaprolactone/Carboxymethyl Cellulose Scaffolds by Mechanical and Thermal Analysis
}

\author{
Noppadol Sriputtha \\ Department of Advanced Manufacturing Technology \\ Faculty of Engineering \\ Pathumwan Institute of Technology \\ Bangkok, Thailand \\ Ido17877@gmail.com
}

\author{
Fasai Wiwatwongwana \\ Department of Advanced Manufacturing Technology \\ Faculty of Engineering \\ Pathumwan Institute of Technology \\ Bangkok, Thailand \\ fasaiw227@gmail.com
}

\author{
Nattawit Promma \\ Department of Mechanical Engineering \\ Faculty of Engineering \\ Chiang Mai University \\ Chiang Mai, Thailand \\ nano_504@hotmail.com
}

\begin{abstract}
The objective of this work was to learn more about three-dimensional porous scaffolds made from biomaterial based on polycaprolactone (PCL) containing different amounts of carboxymethyl cellulose (CMC) nanoparticles. Composite material samples containing $0,2,6.5,11,15.5$, and $20 \%$ w/w of CMC and PCL/CMC scaffolds were prepared with the use of the salt particle leached technique. The mechanical properties were evaluated with the compressive strength analysis method. The studied temperature range started at very low temperatures and ended at crosslinking temperatures. It was evaluated using the thermal analysis methods of Differential Scanning Calorimetry (DSC) in the range $0^{\circ} \mathrm{C}-200^{\circ} \mathrm{C}$. The results revealed that the compressive modulus of blended PCL/CMC scaffold was higher than the one of pure PCL scaffold (582.2 $\pm 106.2 \mathrm{kPa}$ for pure PCL scaffold and $612.2 \pm 296 \mathrm{kPa}$ for blended scaffold which contained $20 \%$ of CMC). For DSC analysis, in addition to the $15.5 \% \mathrm{w} / \mathrm{w}$ CMC PCL/CMC composite scaffold, other proportions of composite materials showed a decrease in crystallization temperature. The crystallinity of PCL-20\% CMC was higher than that of PCL scaffolds.
\end{abstract}

Keywords-polycaprolactone; carboxymethyl cellulose; compressive strength; thermal analysis; differential scanning calorimetry

\section{INTRODUCTION}

Damage or loss of tissue or a portion of the body is usually one of the most deadly and costly problems in health care [1]. Tissue engineering has grown in popularity as a result of the necessity to consider merging or engaging multi-skilled approaches in order to solve this medical problem. Medical progress, along with increasing interaction in a range of fields of knowledge such as materials science, biology, engineering, and physics, has produced breakthroughs in the diagnosis, evaluation, and implementation of implant instruments and tissue transplantation. Extraction of isolated cells, execution with tissue-persuasion chemicals, and implantation of a cell into a scaffold composite are common approaches for tissue regeneration $[3,4]$. In addition, the usage of composite scaffold typically yields more lucrative outcomes [2].

Nanotechnology has become one of the world's fastest expanding industrial sectors, influencing a wide range of scientific and technology industries [5]. Scaffolds are critical components in tissue engineering. When it comes to choosing scaffolds for tissue engineering however, researchers are usually presented with a confusing number of choices [6]. Polymers have been utilized as biomaterials in the manufacturing of medical devices and tissue-engineering scaffolds $[7,8]$. The most recent scaffolds mimic biological processes in the extracellular matrix in order to capture the structure and functions of growing tissues and aid cell adhesion, growth, and dispersal [9]. Biodegradable polymers such as PCL, PLLA, PLGA, etc. are used as scaffolds in tissue engineering to foster cells until they are replaced by the Extracellular Matrix (ECM) [10-12]. An ideal scaffold should be extremely porous with linked pores, biodegradable, and made of components that are compatible. Even though most scaffolds comply with these parameters, their final features are mostly defined by their technique of construction. However, the approach is determined by the goal of the tissue engineering application [13-14]. Three-dimensional porous scaffolds can be prepared using a variety of processes, including 3D printing, phase separation, gas-foaming, solvent casting, salt particle leaching, and freeze-drying [15-17]. 
Particulate leaching has been employed in tissue engineering since it is one of the simplest methods used to create porous materials using salt. The method of salt leaching is simple and does not need the use of high pressure or expensive equipment [18-20]. Controlling of porosity, pore structure, and pore size is as easy as changing the quantity and particle size of salt. In this work, scaffolds were fabricated using the salt particulate leaching method. Polycaprolactone (PCL) is a linear aliphatic polyester. It is a hydro-phobic, biocompatible, semi-crystalline, slowly disintegrating polymer which is simple to work with [21-24]. As a result, a PCL composite based material with tunable hydrophilicity is utilized. The changed hydrophilicity was achieved by offering different magnitudes of a highly hydrophilic biocompatible substance, such as carboxymethyl cellulose (CMC) [21]. The current study investigated the properties of porous scaffolds made of PCL and CMC. The morphological, thermal, and mechanical characteristics of PCL/CMC composite material samples containing $0,2,6.5,11,15.5$, and $20 \% \mathrm{w} / \mathrm{w} \mathrm{CMC}$ were studied.

\section{EXPERIMENTAL PART}

\section{A. Materials}

PCL with an average molecular weight $(\mathrm{Mw})$ of $45 \mathrm{~g} / \mathrm{mol}$ and melting temperature of $56-64^{\circ} \mathrm{C}$, and $\mathrm{CMC}$ with a medium viscosity, were acquired from Sigma-Aldrich, USA. Sodium chloride $(\mathrm{NaCl})$, which will be used as a porogen, was received from Merck KGaA (Darmstadt, Germany). Trifluoroethanol (TFE) from Sigma-Aldrich was employed as a solvent for these composite polymers.

\section{B. Scaffold Preparation}

The scaffolds were fabricated using the salt leaching method. A polymer solution was made by combining a PCL pellet with CMC (PCL/CMC), with TFE as a solvent at a concentration of $30 \%$ (by mass). The PCL solution contained $3 \mathrm{~g}$ of PCL and $7 \mathrm{~g}$ of TFE $[25,26]$. The mixture design parameter in the Minitab software was used to generate the design of the PCL and blended PCL with CMC mixing formulations, as shown in Table I. Codes were used to name the materials, with P0 being the pure base material of PCL produced by mixing a PCL pellet and TFE at a $30 \%$ concentration (by mass). The salt was mixed into the solution, which is utilized for $24 \mathrm{~g}$ [27]. The pure PCL P0 sample (6g) was used for comparison. The weight ratios of the P1-P5 samples were 5.88:0.12, 5.61:0.39, 5.34:0.66, 5.07:0.93, and 4.80:1.20 respectively.

TABLE I. SOLUTION ABBREVIATIONS AND COMPOSITIONS

\begin{tabular}{|c|c|c|}
\hline Sample & PCL \% (w/w) & CMC \% (w/w) \\
\hline P0 & 100 & - \\
\hline P1 & 98 & 2 \\
\hline P2 & 93.5 & 6.5 \\
\hline P3 & 89 & 11 \\
\hline P4 & 84.4 & 15.5 \\
\hline P5 & 80 & 20 \\
\hline
\end{tabular}

\section{Porous Scaffold Fabrication}

In this process, scaffolds were produced by casting a mixture of polymer solution and salt particles. Following solvent evaporation, the scaffolds were fractionated in a suitable solvent, allowing particles to be leached off. Porous scaffolds were formed when these particles were completely eliminated from the mixture [19]. First, the PCL was melt on a stirrer at $55-65^{\circ} \mathrm{C}$ and then the TFE solvent was added to make a $30 \%$ PCL solution. The CMC was poured, stirred, and mixed into the PCL solution until the solution became homogeneous. The $\mathrm{NaCl}$ was then stirred into the mixed PCL/CMC solution. The solution was poured into a teflon mold, which produced $20 \mathrm{~mm}$ edge cube molds. The molds were placed under a ventilation hood overnight to allow the solvent to evaporate. After the solvent evaporated, deionized water was used to leach off the salt particles. The scaffolds were then air dried for two days before being stored in a desiccator. The produced saltleached PCL/CMC scaffolds revealed strongly linked porosity networks.

\section{Morphological Characterization}

Optical and electron microscopy were used to examine the morphology of the scaffolds. A COXEM model EM-30 Plus was used with $20 \mathrm{kV}$ acceleration voltage. Scanning Electron Microscopy (SEM) was utilized as a measurement technique to quantify the average pore size. The average pore size of each component was calculated after measuring at least 20 different pore sizes. The porosity of the scaffold was determined using a specific gravity bottle with ethanol as the fluid in motion, according to the Archimedes hypothesis [28-30]. Finally, the porosity of a scaffold was determined by:

$$
\operatorname{Porosity}(\%)=\frac{\left(\mathrm{W}_{2}-\mathrm{W}_{3}-\mathrm{W}_{\mathrm{S}}\right) / \rho_{\mathrm{e}}}{\left(\mathrm{W}_{1}-\mathrm{W}_{3}\right) / \rho_{\mathrm{e}}} \times 100
$$

where $\mathrm{W}_{1}, \mathrm{~W}_{2}$, and $\mathrm{W}_{3}$ represent the weights of specific gravity bottles containing ethanol, both ethanol and scaffold, and a taken out of ethanol-saturated scaffold respectively, $\mathrm{W}_{\mathrm{S}}$ represents the weight of the scaffold, and $\rho_{\mathrm{e}}$ represents the ethanol density.

\section{E. Mechanical Testing}

PCL has been extensively researched in bone tissue engineering. Long bones respond better to compression stresses than other types of loads [31]. As a result, it was customary to investigate the compression properties of a material that was intended to be utilized for bone replacement [32-34].

The compressive mechanical properties of scaffolds were tested using a Zwick Roell universal testing machine. Five replicas of scaffolds were cut into rectangular pieces of $10 \mathrm{~mm}$ length, $10 \mathrm{~mm}$ width, and around $3 \mathrm{~mm}$ thickness [31]. The crosshead speed was set at $1 \mathrm{~mm} / \mathrm{min}$. The compression modulus was computed by taking the first part of the linear segment of the stress-strain curve and dividing it by the initial cross-sectional area. The parameters were computed in accordance with the processes outlined in the ASTM D3574 standard.

\section{F. Thermal Analysis}

To investigate the temperature behavior of the PCL/CMC composite scaffold, a differential scanning calorimeter (DSC $3+$, Mettler Toledo, Switzerland) was used. The samples were 
around $10 \mathrm{mg}$ in weight [4]. All samples were put in a hermetically sealed aluminum pan with a nitrogen flow rate of $50 \mathrm{~mL} / \mathrm{min}$. The samples were heated for $5 \mathrm{~min}$ at temperatures ranging from 0 to $200^{\circ} \mathrm{C}$ before being cooled to $0^{\circ} \mathrm{C}$ and reheated to $200^{\circ} \mathrm{C}$. The ramp rate was $10^{\circ} \mathrm{C} / \mathrm{min}$ during all heating and cooling cycles [35].

\section{RESULTS AND DISCUSSION}

\section{A. Morphological Analysis}

After being coated with gold by an ion-sputter machine. (Ion-Coater, a COXEM SPT-20), the porous scaffold was studied for morphological characterization using SEM (COXEM model EM-30 Plus) at $20 \mathrm{kV}$. The dimension of the pore size was measured for at least 20 pores $[15,26]$ and the average pore size was calculated as shown in Figure 1. Figure 1 shows the P0, P1, P2, P3, P4, and P5 occurring pore diameters of $227.35,269.48,348.28,271.82$, and $284.70 \mathrm{~mm}$ respectively. The average porosity of the PCL (P0) scaffold was $81.44 \%$ and the porosities of the blended P1 to P5 scaffolds were 98.70 , $98.30,98.73,98.06$, and $98.88 \%$. The porosity of blended PCL/CMC scaffolds was higher than that of the pure PCL scaffold, which might be due to CMC particles being dispersed throughout the PCL matrix surrounding the scaffold [27].

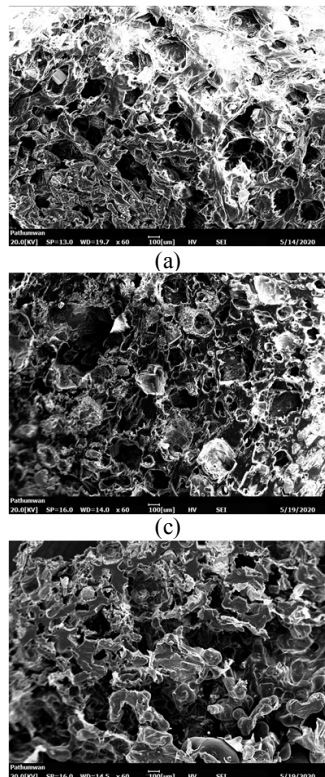

(e)

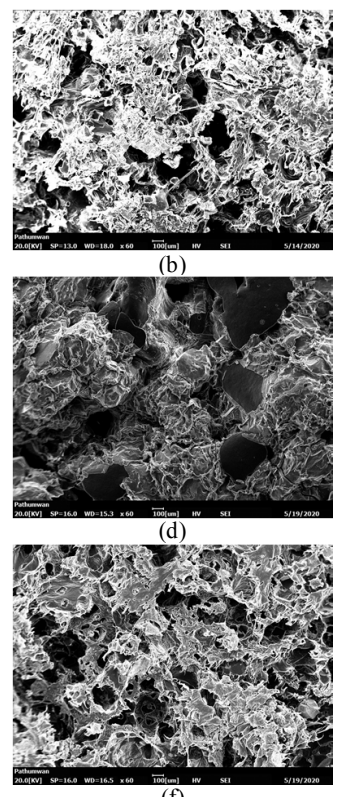

(f)
Fig. 1. SEM images of PCL and PCL/CMC composite scaffolds, (a) P0, (b) P1, (c) P2, (d) P3, (e) P4, and (f) P5.

\section{B. Morphological Analysis}

Adding CMC loading had a detrimental influence on the mechanical characteristics of the composite scaffolds [36]. As demonstrated in Table II, the compression modulus decreased as the additive concentration of $\mathrm{CMC}$ increased. The decreasing of CMC was not significantly different $(p>0.05)$ when compared to P0 scaffold as shown in Figure 2 which shows the apparent compressive modulus of PCL and composite scaffolds. P0, P3, P4, and P5 scaffolds demonstrated mechanical behavior with a consistent pattern within each group. P1 and P2 scaffolds, on the other hand, exhibited mechanical behavior with more diversity. The P2 mixture showed the highest compressive modulus which was $789.6 \mathrm{kPa}$, whereas the P3 mixture showed the lowest compressive modulus which was $509 \mathrm{kPa}$. P1, P4, and P5 had compressive moduli of $706,605.4$ and $612.2 \mathrm{kPa}$, respectively. The compression modulus values were compared with the reported results of previous studies. The results obtained in this work for PCL scaffold, as well as the values published in [31] were close to the lower limit of the homogeneous compression modulus range.

TABLE II. COMPRESSIVE MODULUS OF THE BLENDED SCAFFOLDS

\begin{tabular}{|c|c|}
\hline Scaffolds & Compressive modulus (kPa) \\
\hline P0 & $582 \pm 106$ \\
\hline P1 & $706 \pm 39$ \\
\hline P2 & $789.6 \pm 183$ \\
\hline P3 & $509 \pm 225$ \\
\hline P4 & $605.4 \pm 124$ \\
\hline P5 & $612.2 \pm 296$ \\
\hline
\end{tabular}

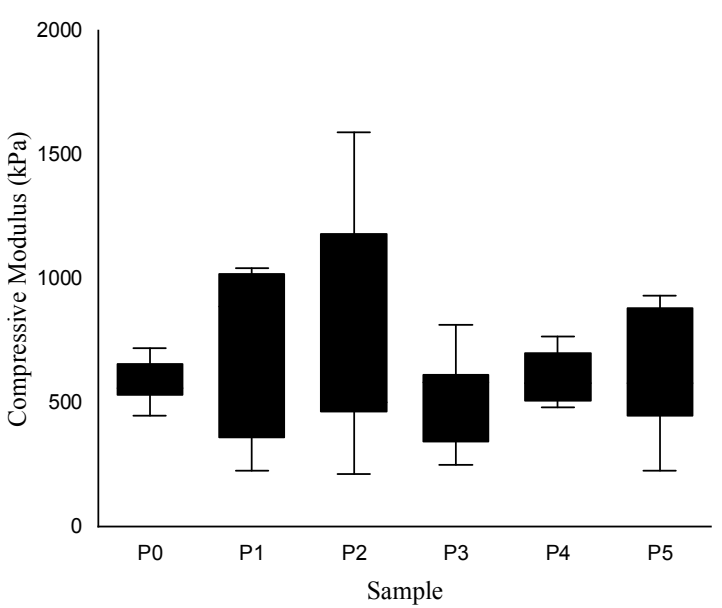

Fig. 2. Comparison of the compressive modulus of PCL/CMC blended scaffolds.

\section{Differential Scanning Calorimetry}

Figure 3 shows the DSC results taken during the second heating, and Table III shows the measured parameters. With these data, melting temperature (Tm), and melting enthalpy $(\Delta \mathrm{Hm})$ were obtained. Crystallinity $(\mathrm{Xc})$ was determined using (2). The considered melting enthalpy of the $100 \%$ crystalline PCL ( $\Delta$ Ho) was $146 \mathrm{~J} / \mathrm{g}$ [37].

$$
\mathrm{X}_{\mathrm{c}}=\frac{\Delta \mathrm{H}_{\mathrm{m}}}{\Delta \mathrm{H}_{\mathrm{o}}}
$$

The sample P4 showed the greatest peak melting temperature, a melting enthalpy of $83.27 \mathrm{~J} / \mathrm{g}$, and a crystallinity of $57.0 \%$. Other authors discovered that the addition of CMC to PLC had no effect on melting temperature [38], however their experiments were restricted to increase of up to $20 \%$ by weight of CMC in particular. Authors in $[2,21,31]$ reported that combining $20 \% \mathrm{CMC}$ with PCL raised the melting temperature by $1{ }^{\circ} \mathrm{C}$. We observed that the $20 \%$ CMC scaffold exhibited a consistent melting temperature change of about 
$1{ }^{\circ} \mathrm{C}$. It was found that the melting temperature was $68^{\circ} \mathrm{C}$ with $10 \% \mathrm{CMC}$ addition [22], and $67.31^{\circ} \mathrm{C}$ for $11 \% \mathrm{CMC}$ addition in this investigation.

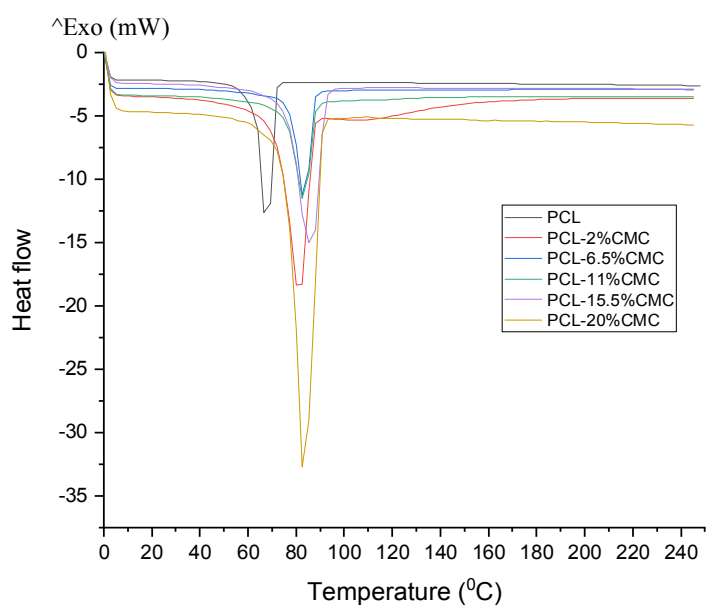

Fig. 3. Heating DSC scan for PCL and its composite scaffolds.

TABLE III. COMPRESSIVE MODULI OF THE PCL/CMC BLENDED SCAFFOLDS

\begin{tabular}{|c|c|c|c|}
\hline Samples & $\mathbf{T m}\left({ }^{\circ} \mathbf{C}\right)$ & $\Delta \mathbf{H m}(\mathbf{J} / \mathbf{g})$ & $\mathbf{X c}(\mathbf{\%})$ \\
\hline P0 & 67.31 & 59.35 & 40.65 \\
\hline P1 & 65.43 & 57.62 & 39.46 \\
\hline P2 & 67.79 & 23.13 & 15.84 \\
\hline P3 & 67.31 & 23.04 & 15.78 \\
\hline P4 & 69.53 & 83.27 & 57.03 \\
\hline P5 & 66.49 & 81.59 & 55.88 \\
\hline
\end{tabular}

\section{Discussion}

According to the results of these experiments, the PCL/CMC mixture of 93.5/6.5 (P2) combined the maximum compressive modulus with a good porosity value and interconnected porous structures that reacted similarly to other circumstances. The presence of CMC mitigated the degradation temperature and decreased it continuously as the amount of CMC rised. The blended PCL/CMC scaffolds P1-P5 were fabricated using the salt leaching method which could be used for tissue engineering applications. However, the amount of $\mathrm{CMC}$ used should be sufficient to alter the hydrophilicity of the scaffold. The melting temperature of $\mathrm{P} 4$ was the highest $\left(89.53^{\circ} \mathrm{C}\right)$, with a melting enthalpy of $83.27 \mathrm{~J} / \mathrm{g}$ and a crystallinity of $57.03 \%$, whereas the melting temperatures of the other components were quite comparable. This might imply that the addition of MC to the PCL had no influence on the melting temperature.

\section{CONCLUSION}

The salt leaching method was used in this work to effectively fabricate PCL/CMC composite scaffolds. Using the solvent cast salt leaching method, it was feasible to create homogeneous PCL/CMC composite scaffolds with efficiently distributed homogenous porous structure. The scaffold from salt leaching with the mixture of PCL-6.5\% CMC (P2) ratio showed the greatest compressive modulus, which was
$789.6 \mathrm{kPa}$, whereas the combination of PCL-11\% CMC (P3) ratio had the lowest compressive modulus, which was $509 \mathrm{kPa}$. The ratios $\mathrm{P} 4$ and $\mathrm{P} 5$ were lower than $\mathrm{P} 3$, but they were higher than the PCL. In summary, adding CMC to PCL can improve the mechanical characteristics of the scaffold. With the exception of the $15.5 \% \mathrm{w} / \mathrm{w} \mathrm{CMC}$, the PCL/CMC composite scaffolds showed decreasing in crystallization temperature, enthalpy of crystallization, melting enthalpy, and crystallinity degree in DSC analysis. In addition, the crystallinity of PCL$20 \%$ CMC is higher than that of PCL. Because of their biocompatible and biodegradable properties, making them suitable for support materials in biomedical engineering and pharmacological applications, the PCL/CMC scaffolds exhibited characteristics that need further investigation.

\section{REFERENCES}

[1] N. U. Kang, M. W. Hong, Y. Y. Kim, Y. S. Cho, and S. J. Lee, "Development of a Powder Extruder System for Dual-pore Tissueengineering Scaffold Fabrication," Journal of Bionic Engineering, vol. 16, no. 4, pp. 686-695, Jul. 2019, https://doi.org/10.1007/s42235-0190055-y.

[2] M. E. Alemán-Domínguez, E. Giusto, Z. Ortega, M. Tamaddon, A. N. Benítez, and C. Liu, "Three-dimensional printed polycaprolactonemicrocrystalline cellulose scaffolds," Journal of Biomedical Materials Research - Part B Applied Biomaterials, vol. 107, no. 3, pp. 521-528, 2019, https://doi.org/10.1002/jbm.b.34142.

[3] Y. L. Qiu et al., "Characterization of different biodegradable scaffolds in tissue engineering," Molecular Medicine Reports, vol. 49, no. 5, pp. 4043-4056, May 2019, https://doi.org/10.3892/mmr.2019.10066.

[4] Z. Yang, X. Li, J. Si, Z. Cui, and K. Peng, "Morphological, Mechanical and Thermal Properties of Poly(lactic acid) (PLA)/Cellulose Nanofibrils (CNF) Composites Nanofiber for Tissue Engineering," Journal Wuhan University of Technology, Materials Science Edition, vol. 34, no. 1, pp. 207-215, 2019, https://doi.org/10.1007/s11595-019-2037-7.

[5] Z. Y. Ilerisoy and Y. Takva, "Nanotechnological Developments in Structural Design: Load-Bearing Materials," Engineering, Technology \& Applied Science Research, vol. 7, no. 5, pp. 1900-1903, 2017, https://doi.org/10.48084/etasr.1414.

[6] S. Pina et al., "Scaffolding Strategies for Tissue Engineering and Regenerative Medicine Applications," Materials, vol. 12, no. 11, p. 1824, 2019, https://doi.org/https://doi.org/10.3390/ma12111824.

[7] F. Tondnevis, M. Ketabi, R. Fekrazad, A. Sadeghi, and M. M. Abolhasani, "Using chitosan besides nano hydroxyapatite and fluorohydroxyapatite boost dental pulp stem cell proliferation," Journal of Biomimetics, Biomaterials and Biomedical Engineering, vol. 42, pp. 39-50, 2019, https://doi.org/10.4028/www.scientific.net/JBBBE.42.39.

[8] M. F. Abdelkarim, L. S. Nasrat, S. M. Elkhodary, A. M. Soliman, A. M. Hassan, and S. H. Mansour, "Volume Resistivity and Mechanical Behavior of Epoxy Nanocomposite Materials," Engineering, Technology \& Applied Science Research, vol. 5, no. 2, pp. 775-780, 2015, https://doi.org/10.48084/etasr.536.

[9] A. Eltom, G. Zhong, and A. Muhammad, "Scaffold Techniques and Designs in Tissue Engineering Functions and Purposes: A Review," Advances in Materials Science and Engineering, vol. 2019, 2019, Art. no. 3429527, https://doi.org/10.1155/2019/3429527.

[10] E. Sabzi, F. Abbasi, and H. Ghaleh, "Interconnected porous nanofibrous gelatin scaffolds prepared via a combined thermally induced phase separation/particulate leaching method," Journal of Biomaterials Science, Polymer Edition, vol. 32, no. 4, pp. 488-503, 2020, https://doi.org/10.1080/09205063.2020.1845921.

[11] M. Bazgir et al., "Degradation and Characterisation of Electrospun Polycaprolactone (PCL) and Poly(lactic-co-glycolic acid) (PLGA) Scaffolds for Vascular Tissue Engineering Morteza," Materials, vol. 14, no. 15, 2021, Art. no. 4773, https://doi.org/https://doi.org/10.3390/ ma14174773. 
[12] L. Siad et al., "FEA Based on 3D Micro-CT Images of Mesoporous Engineered Hydrogels," Engineering, Technology \& Applied Science Research, vol. 5, no. 6, pp. 885-890, 2015, https://doi.org/10.48084/ etasr.606.

[13] J. L. Walker and M. Santoro, "Processing and production of bioresorbable polymer scaffolds for tissue engineering," in Bioresorbable Polymers for Biomedical Applications: From Fundamentals to Translational Medicine, Amsterdam, Neatherlands: Elsevier Ltd, 2017, pp. 181-203.

[14] Y. S. Cho, S. J. Gwak, and Y. S. Cho, "Fabrication of polycaprolactone/nano hydroxyapatite (Pcl/nha) 3d scaffold with enhanced in vitro cell response via design for additive manufacturing (dfam)," Polymers, vol. 13, no. 9, May 2021, Art. no. 1394, https://doi.org/10.3390/polym13091394.

[15] Y. Morpara and F. Wiwatwongwana, "Characterization of gelatin/cmc scaffold fabricated by using salt leaching technique," in Materials Science Forum, 2019, vol. 962, pp. 129-136, https://doi.org/ 10.4028/www.scientific.net/MSF.962.129.

[16] K. Zhang et al., "Fabrication of highly interconnected porous poly( $\varepsilon$ caprolactone) scaffolds with supercritical $\mathrm{CO} 2$ foaming and polymer leaching," Journal of Materials Science, vol. 54, no. 6, pp. 5112-5126, Mar. 2019, https://doi.org/10.1007/s10853-018-3166-7.

[17] A. Haider et al., "Advances in the scaffolds fabrication techniques using biocompatible polymers and their biomedical application: A technical and statistical review," Journal of Saudi Chemical Society, vol. 24, no. 2, pp. 186-215, 2020, https://doi.org/10.1016/j.jscs.2020.01.002.

[18] A. Sola et al., "Development of solvent-casting particulate leaching (SCPL) polymer scaffolds as improved three-dimensional supports to mimic the bone marrow niche," Materials Science and Engineering $C$, vol. 96, pp. 153-165, Mar. 2019, https://doi.org/10.1016/j.msec. 2018.10.086.

[19] M. Roshandel and F. Dorkoosh, "Cardiac tissue engineering, biomaterial scaffolds, and their fabrication techniques," Polymers for Advanced Technologies, vol. 32, no. 6, pp. 2290-2305, 2021, https://doi.org/ 10.1002/pat.5273.

[20] L. Sardelli, D. P. Pacheco, L. Zorzetto, C. Rinoldi, W. Święszkowski, and P. Petrini, "Engineering biological gradients," Journal of Applied Biomaterials and Functional Materials, vol. 17, no. 1, 2019, https://doi.org/10.1177/2280800019829023.

[21] M. E. Alemán-Domínguez, Z. Ortega, A. N. Benítez, G. VilariñoFeltrer, J. A. Gómez-Tejedor, and A. Vallés-Lluch, "Tunability of polycaprolactone hydrophilicity by carboxymethyl cellulose loading," Journal of Applied Polymer Science, vol. 135, no. 14, Apr. 2018, https://doi.org/10.1002/app.46134.

[22] R. Dwivedi et al., "Polycaprolactone as biomaterial for bone scaffolds: Review of literature," Journal of Oral Biology and Craniofacial Research, vol. 10, no. 1, pp. 381-388, 2020, https://doi.org/10.1016/ j.jobcr.2019.10.003.

[23] S. Kashte, G. Arbade, R. K. Sharma, and S. Kadam, "Herbally Painted Biofunctional Scaffolds with Improved Osteoinductivity for Bone Tissue Engineering," Journal of Biomimetics, Biomaterials and Biomedical Engineering, vol. 41, pp. 49-68, 2019, https://doi.org/10.4028/www. scientific.net/jbbbe.41.49.

[24] B. Aaliya, K. V. Sunooj, and M. Lackner, "Biopolymer composites: a review," International Journal of Biobased Plastics, vol. 3, no. 1, pp. 40-84, 2021, https://doi.org/10.1080/24759651.2021.1881214.

[25] C. G. Simon, "Scaffold Fabrication Tutorial: Salt-Leaching \& Gas Foamed Scaffolds," [Online]. Available: https://www.nist.gov/system/ files/documents/mml/bbd/biomaterials/Scaffold-Fabrication-Tutorial. pdf.

[26] K. R. Coogan, P. T. Stone, N. D. Sempertegui, and S. S. Rao, "Fabrication of micro-porous hyaluronic acid hydrogels through salt leaching," European Polymer Journal, vol. 135, 2020, Art. no. 109870 , https://doi.org/10.1016/j.eurpolymj.2020.109870.

[27] N. Sriputtha, F. Wiwatwongwana, and N. Promma, "Fabrication of Porous Polycaprolactone/Carboxymethylcellulose Scaffolds by using Salt Leaching Technique," Journal of Wuhan University of TechnologyMaterials Science Edtion, 2022, (in press).
[28] P. Balaji, A. Murugadas, S. Shanmugaapriya, and M. Abdulkader Akbarsha, "Fabrication and characterization of egg white cryogel scaffold for three-dimensional (3D) cell culture," Biocatalysis and Agricultural Biotechnology, vol. 17, pp. 441-446, 2019, https://doi.org/ 10.1016/j.bcab.2018.12.019.

[29] Y. Gong et al., "Experimental investigation and optimal 3D bioprinting parameters of sa-gel porous cartilage scaffold," Applied Sciences (Switzerland), vol. 10, no. 3, 2020, Art. no. 768, https://doi.org/ 10.3390/app10030768.

[30] C. H. Cheng, Y. W. Chen, A. Kai-Xing Lee, C. H. Yao, and M. Y. Shie, "Development of mussel-inspired 3D-printed poly (lactic acid) scaffold grafted with bone morphogenetic protein-2 for stimulating osteogenesis," Journal of Materials Science: Materials in Medicine, vol. 30, no. 7, 2019, Art. no. 78, https://doi.org/10.1007/s10856-019-6279-x.

[31] M. E. Alemán-Domínguez et al., "Polycaprolactone-carboxymethyl cellulose composites for manufacturing porous scaffolds by material extrusion," Bio-Design and Manufacturing, vol. 1, no. 4, pp. 245-253, Dec. 2018, https://doi.org/10.1007/s42242-018-0024-z.

[32] Y. Zamani et al., "3D-printed poly(E-caprolactone) scaffold with gradient mechanical properties according to force distribution in the mandible for mandibular bone tissue engineering," Journal of the Mechanical Behavior of Biomedical Materials, vol. 104, 2019, Art. no. 103638, 2020, https://doi.org/10.1016/j.jmbbm.2020.103638.

[33] Q. Wang, Z. Ma, Y. Wang, L. Zhong, and W. Xie, "Fabrication and characterization of 3D printed biocomposite scaffolds based on PCL and zirconia nanoparticles," Bio-Design and Manufacturing, vol. 4, no. 1, pp. 60-71, 2021, https://doi.org/10.1007/s42242-020-00095-3.

[34] W. Wang, B. Huang, J. J. Byun, and P. Bártolo, "Assessment of $\mathrm{PCL} /$ carbon material scaffolds for bone regeneration," Journal of the Mechanical Behavior of Biomedical Materials, vol. 93, pp. 52-60, 2019, https://doi.org/10.1016/j.jmbbm.2019.01.020.

[35] Z. Jiao, B. Luo, S. Xiang, H. Ma, Y. Yu, and W. Yang, "3D printing of HA / PCL composite tissue engineering scaffolds," Advanced Industrial and Engineering Polymer Research, vol. 2, no. 4, pp. 196-202, Oct. 2019, https://doi.org/10.1016/j.aiepr.2019.09.003.

[36] J. Si, J. Lin, Z. Zheng, Z. Cui, and Q. Wang, "Fabrication and Characterization of 3D Graded PDMS Scaffolds Using VacuumAssisted Resin Transfer Moulding," Journal Wuhan University of Technology, Materials Science Edition, vol. 33, no. 5, pp. 1263-1270, 2018, https://doi.org/10.1007/s1 1595-018-1961-2.

[37] C. B. B. Luna, D. D. Siqueira, E. da S. B. Ferreira, E. M. Araújo, and R. M. R. Wellen, "Effect of injection parameters on the thermal, mechanical and thermomechanical properties of polycaprolactone (PCL)," Journal of Elastomers and Plastics, vol. 53, no. 8, pp. 10451062, 2021, https://doi.org/10.1177/00952443211015345.

[38] E. Díaz, J. Aresti, and J. León, "Evaluation of physicochemical and mechanical properties with the in vitro degradation of $\mathrm{PCL} / \mathrm{nHA} / \mathrm{MWCNT}$ composite scaffolds," Journal of Reinforced Plastics and Composites, vol. 40, no. 3-4, pp. 134-142, 2021, https://doi.org/10.1177/0731684420943304. 